\title{
Patient mobility in the global marketplace: a multidisciplinary perspective
}

\author{
Neil Lunt ${ }^{1, *}$, Russell Mannion ${ }^{2}$
}

\section{Abstract}

There is a growing global market in healthcare and patients. And while there is a small body of evidence emerging around this phenomenon commonly known as medical tourism there remain significant unanswered policy and research questions which need to be addressed. We outline some of the key issues set against the six key disciplinary preoccupations of the journal: epidemiology, health economics, health policy ethics, politics of health, health management, and health policy.

Keywords: Medical Tourism, Patient Mobility, Cross-Border Care, International Patients, Private Healthcare Copyright: @ 2014 by Kerman University of Medical Sciences

Citation: Lunt N, Mannion R. Patient mobility in the global marketplace: a multidisciplinary perspective. Int $J$ Health Policy Manag 2014; 2: 155-157. doi: 10.15171/ijhpm.2014.47
Article History:

Received: 26 April 2014

Accepted: 13 May 2014

ePublished: 14 May 2014

Correspondence to:

Neil Lunt

Email: neil.lunt@york.ac.uk

\section{Background}

Over recent decades a combination of push and pull factors have acted as a catalyst for promoting the rise of international travel for the purposes of medical treatment - this is commonly known as medical tourism. Key factors associated with the rise in the global movement of patients across international borders include the growing globalisation and inter-connectedness of economic production and trade, new forms of political cooperation, technological developments, and a burgeoning international market in medical care and services provided by health professionals. Medical services offered to patients willing to travel to other countries for medical care encompass a wide variety of services including bio-ethical treatments (fertility, transplantation and stem cell therapies), diagnostic tests, and cosmetic, orthopaedic, eye and heart surgery.

The willingness of patients to seek medical services across international borders is not a new phenomenon-social elites have always travelled to be treated in more advanced health care systems. Regional centres have also existed within the Middle East where wealthy patients from the Gulf States have been willing to travel to Beirut, Cairo and Jordon (1). However we are now experiencing both a quantitative and qualitative shift in patient mobility. In particular we are witnessing unprecedented numbers of patients travelling from richer, more developed nations to less developed countries to access health services. These shifts are largely driven by the relative low-cost of treatment in less developed nations, the availability of cheap flights and increased online marketing and consumer information about the availability of medical services.

There are different drivers motivating patients to travel, diverse sources of funding to support patient mobility and a variety of models of delivering care to medical tourists (2-4). The world map of destinations frequented by medical tourists would now include a range of competing European destinations (Western, Scandinavian, Central and Southern Europe, Mediterranean), East and South Asia (India, Malaysia, Singapore, Korea and Thailand); South Africa; South and
Central America (including Brazil, Costa Rica, Cuba and Mexico); the Middle East (particularly Dubai and Jordon). It appears that geographical proximity is an important, but not decisive, factor in shaping providers' marketing plans, with many providers targeting potential patients from local regions $(5,6)$. Movement can be both funded out-of-pocket or government financed with state support for patient mobility driven particularly by a lack of available specialists and specialised equipment in home countries.

Deloitte have suggested that the number of US citizens leaving the country in search of medical care stood at 750,000 in 2007 and projected that the number of medical tourists would be between 3 and 5 million by 2010. As US medical tourists are thought to represent approximately $10 \%$ of the global number of medical travellers this would give a global figure of between 30 and 50 million medical tourists travelling for treatment each year (7). However, analysts at McKinsey argue that a more accurate worldwide figure would be between 60,000 and 85,000 medical tourists travelling per year although, these numbers do appear rather small and unrealistic (8). It is reported, for example, that the Bumrungrad hospital in Bangkok had admitted close to 500,000 patients in 2003 (9). By 2005, the hospital admitted 93,000 Arab patients alone (10). Given that even conservative estimates of medical travellers to India put the number at 200,000 (11), alongside figures of 200,000 for Cuba (12) and around 60,000 for the UK (13), it would seem that the numbers cited by McKinsey are unrealistically low. Having outlined some of the key changes in patient mobility that have emerged over recent decades we now consider the key challenges in relation to medical tourism under the six key disciplinary preoccupations of the Journal.

\section{Epidemiology}

As noted above, robust and credible data on the numbers and flows of medical tourists between nations and the background characteristics of medical tourists are notoriously difficult to obtain. While there is a general consensus that the medical 
tourism industry has grown over recent years, and that there are well established flows between particular countries and geographical regions, there is ongoing debate as to the actual and potential size of the medical tourism market. Indeed the task of compiling robust figures on medical tourists is beset by a number of challenges including a range of rival and competing definitions, difficulties in gaining access to data, problems associated with ascertaining the motivations of travelling patients, and the commercial interests of providers (14).

Evidence about the clinical outcomes of treatments undertaken abroad is also limited. Little is currently known about the relative clinical effectiveness and outcomes for particular treatments provided by different institutions, clinicians and organisations used by medical tourists. Evidence is also lacking on long or short-term follow-up of patients returning to their home countries. The overseas and (predominantly) private nature of delivery may explain why there is such a dearth of information about clinical outcomes, post-operative complications, lapses in safety, infection and poor professional practice (15).

\section{Health economics}

Given the travel patterns of medical tourists, the economic implications of medical travel are of increasing concern to national governments. Financial impacts for source countries include the costs that result from overseas surgical treatment requiring emergency or remedial treatment within home countries as well as the attendant health and social care costs. On the other hand, health systems may accrue financial savings from citizens travelling overseas for treatment. To date there is little systemic collection of evidence or attempts to estimate overall health system costs and benefits of medical tourism. For destination countries, medical tourism holds many attractions for national governments, including the potential revenue generated from health services and associated visitor spending. There are potential human resource benefits with some exporting countries presenting medical tourism as attracting back home country health workers who had emigrated, thus reversing the 'brain drain'. Positive spillovers of medical tourism may include new sources of investment in domestic health services and the diffusion of new medical technologies and care pathways among domestic healthcare providers.

\section{Health policy ethics}

There are ongoing ethical concerns associated with travelling for treatment abroad. Some providers may be prepared to offer treatments that are more risky, or to place different emphasis on the ethical issues involved. Some countries may seek to provide treatments that are illegal or highly experimental (16). For example, rewarded kidney donation is illegal in many but not all parts of the world (17).

At the system level, ethical questions include whether economic and health benefits do trickle down to local populations and the extent to which the use of local healthcare professionals reduces the level and quality of health provision for local populations.

An overarching concern is how the growth of medical tourism contributes towards individual health being further commercialized and commodified (18). Under pressures of commercialization and commodification, relationships become shaped by the less elevated values of commercial gain rather than professional ethical codes (19).

\section{Politics of health}

For most countries seeking to develop medical tourism, prospective providers are typically from the private sectoralthough some country strategies do identify opportunities for the public sector system to expand into this area Medical tourism initiatives are often launched with a great deal of fanfare. Given the country promotion strategies, provider exaggeration, and industry 'grand-standing' it becomes difficult to distinguish rhetoric from reality.

Plausibly, source countries could develop bilateral relations with off-shore medical tourism facilities to leverage cost savings. However, even if opportunities for financial benefit and reduced waiting lists do exist there may remain significant political objections and sensitivities to such outsourcing (20) both for publicly funded systems and those funded through private and occupational health insurance. This for example helps explain why Medicaid and Medicare in the United States do not support patients travelling abroad for treatment despite the argument that this would deliver significant financial savings to the US Treasury.

Questions remain then about the political will that exists to address the system-level impacts. A serious problem when searching for reliable data to inform discussions about risks and opportunities of medical travel is stakeholders with a vested interest who are responsible for providing the data $(5,14)$.

\section{Health management}

Some evidence is now emerging about how medical tourists make decisions over the treatments they seek to access and the destinations to which they travel to $(13,21)$. Patients appear to weigh up different forms of hard data (viz. performance measures, quality markers etc.) with soft intelligence (viz. information provided by websites, the recommendations of family, friends, and exchanges via internet chat rooms) when making their decisions over treatment options. Because prospective travellers source information from intermediaries, direct from websites and internet marketing, and amongst networks, it complicates practical attempts to regulate and enhance the quality of information provided to prospective medical tourists. Website and marketing materials contain a plethora of details on External Quality Assessment (EQA), registration and accreditation. How EQA and registration details are currently presented require significant health literacy among website users. Prospective patients may not be aware of the lack of clear avenues for redress should treatment abroad give rise to unexpected complications. Indeed, legal uncertainty and complexity occurs at all phases of treatment abroad: access to information, preconsultation, treatment itself, aftercare and follow-up.

\section{Health policy}

This growth of medical tourism raises important issues for health policy including how countries should themselves respond, as well as issues in relation to transnational governance as patients cross international boundaries to seek treatment. For destination countries, policy issues include state and regional support for medical tourism development and whether such activities also benefit the domestic population. 
For example, hospitals could plausibly cross-subsidise care for domestic patients, or help to fund capital investment, such as MRI scanners, which are then used by all patients in the hospital or health system.

For source countries, large numbers of medical tourists travelling overseas can potentially impact on the viability of the domestic health system. Large outflows of high-income patients from LMIC for example may reduce revenue and dilute political support for the development of local health services. But it is also within higher income countries where there are possibilities of exacerbating a two-tier healthcare system. If, for example, eligibility for services such as fertility treatment or dental work is tightened, then those individuals with private resources may increasingly circumvent local regulations and elect to travel overseas to obtain treatment.

Payment mechanisms for medical tourism are primarily two-fold: government outsourcing and out of pocket. To date there has been relatively limited success by medical tourist providers in tapping insurance revenue streams. Most private insurance policies in the UK for example explicitly exempt overseas treatment, whilst standard policy exclusions include conception, cosmetic, reconstructive or weight loss treatment and dental/oral treatment. These are the type of treatments where evidence suggests patients then choose to pay out of pocket, both domestically and abroad. Within the United States, examples of institutionalised arrangements do exist but are rare.

\section{Concluding remarks}

Although patient mobility has become an established feature of the global health care landscape we have only limited evidence on who is travelling where and for what purpose to help guide future policy and regulation in this area. The research challenge is therefore to shed more light on this important but under researched area of health policy and as we have outlined this will require integrating insights and approaches from a range of disciplinary perspectives.

Ethical issues

Not applicable.

\section{Competing interests}

The authors declares that they have no competing interests.

\section{Authors' contributions}

$\mathrm{NL}$ and RM contributed equally to the writing of this editorial.

Authors' affiliations

${ }^{1}$ Department of Social Policy and Social Work, University of York, UK. ${ }^{2} \mathrm{Health}$ Services Management Center, University of Birmingham, UK.

\section{References}

1. Kronfol NM. Delivery of health services in Arab countries: a review. East Mediterr Health J 2012; 18: 1229-38.

2. Glinos IA, Baeten R, Helble M, Maarse H. A typology of crossborder patient mobility. Health Place 2010; 16: 1145-55. doi: 10.1016/j.healthplace.2010.08.001

3. Carrera P, Lunt N. A European perspective on medical tourism: the need for a knowledge base. Int J Health Serv 2010; 40: 469-84. doi: 10.2190/hs.40.3.e

4. Lunt N, Smith R, Exworthy M, Green ST, Horsfall D, Mannion
R. Medical Tourism: Treatments, Markets and Health System Implications: A scoping review [internet]. Directorate for Employment, Labour and Social Affairs. OECD: Paris, 2011. Available from: http://www.oecd.org/els/health-systems/48723982. pdf

5. Connell J. Contemporary medical tourism: Conceptualisation, culture and commodification. Tourism Management 2013; 34: 1-13. doi: 10.1016/j.tourman.2012.05.009

6. Ormond ME. Neoliberal governance and International medical travel in Malaysia. Abingdon: Routledge; 2013. doi: 10.4324/9780203077566

7. Keckley PH, Underwood HR. Medical Tourism: Consumers in Search of Value. Washington: Deloitte Center for Health Solutions; 2008.

8. Ehrbeck T, Guevara C, Mango PD. Mapping the Market for Medical Travel. The McKinsey Quarterly [internet]. 2008. Available: https://www.mckinseyquarterly.com/Mapping_the_market_for_ travel_2134

9. McClean K. Medical Tourism: Or, for the politically correct... Cross Border Health Care. Presentation slides. Saskatchewan: University of Saskatchewan; 2008.

10. MacReady N. Developing countries court medical tourists. Lancet 2007; 369: 1849-50. doi: 10.1016/s0140-6736(07)60833-2

11. Crone RK. Flat Medicine? Exploring Trends in the Globalization of Health Care. Acad Med 2008; 83: 117-21. doi: 10.1097/ acm.0b013e318160965c

12. Crozier GKD, Baylis F. The ethical physician encounters international medical travel. J Med Ethics 2010; 36: 297-301. doi: 10.1136/jme.2009.032789

13. Lunt N, Smith RD, Mannion R, Green ST, Exworthy M, Hanefeld, $\mathrm{J}$, et al. Implications for the NHS of inward and outward medical tourism: a policy and economic analysis using literature review and mixed-methods approaches. Health Serv Deliv Res 2014; 2. doi: $10.3310 /$ hsdr02020

14. Lunt N, Hanefeld J, Smith RD, Exworthy M, Horsfall D, Mannion R. Market size, market share and market strategy: three myths of medical tourism. Policy Polit 2013; forthcoming.

15. Alleman BW, Luger T, Reisinger HS, Martin R, Horowitz MD, Cram P. Medical Tourism Services Available to Residents of the United States. J Gen Intern Med 2011; 26: 492-7. doi: 10.1007/s11606010-1582-8

16. Cortez N. Patients without borders: the emerging global market for patients and the evolution of modern health care. Indiana Law J 2008; 83: 71-131.

17. Rouchi AH, Mahdavi-Mazdeh M, Zamyadi M. Compensated living kidney donation in Iran: donor's attitude and short-term follow-up. Iran Kidney Dis 2009; 3: 34-9.

18. Whittaker A. Challenges of medical travel to global regulation: A case study of reproductive travel in Asia. Glob Soc Policy 2010; 10: 396-415. doi: 10.1177/1468018110379981

19. Pellegrino ED. The commodification of medical and health care: the moral consequences of a paradigm shift from a professional to a market ethic. J Med Philos 1999; 24: 243-66. doi: 10.1076/ jmep.24.3.243.2523

20. Smith RD, Martinez-Alvarez M, Chanda R. Medical tourism: a review of the literature and analysis of a role for bi-lateral trade. Health Policy 2011; 103: 276-82. doi: 10.1016/j. healthpol.2011.06.009

21. Cameron K, Crooks V Chouinard V Snyder J, Johnston R, Casey V. Motivation, justification, normalization: Talk strategies used by Canadian medical tourists regarding their choices to go abroad for hip and knee surgeries. Soc Sci Med 2014; 106: 93-100. doi: 10.1016/j.socscimed.2014.01.047 